\title{
Variability in Calanus spp. abundance on fine- to mesoscales in an Arctic fjord: implications for little auk feeding
}

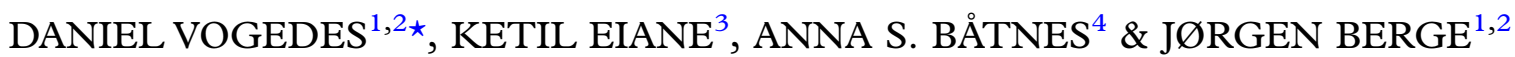 \\ ${ }^{1}$ The University Centre in Svalbard, Longyearbyen, Norway, ${ }^{2}$ Department of Arctic and Marine Biology, University of \\ Tromsø, Norway, ${ }^{3}$ Faculty for Bioscience and Aquaculture, University of Nordland, Bodø, Norway, and ${ }^{4}$ Department of \\ Biology, Norwegian University of Science and Technology, Trondheim Biological Station, Trondheim, Norway
}

\begin{abstract}
We studied the abundance of calanoid copepods of the genus Calanus in a high-resolution sampling grid located in the vicinity of a breeding colony of an avian Calanus predator, the little auk (Alle alle) in an Arctic fjord (Isfjorden, Svalbard) in July 2007. Within diving reach of little auks, all copepodite stages of $C$. finmarchicus, as well as stages CIII-CV of $C$. glacialis, were recorded in all 26 stations sampled. Spatial autocorrelation analysis was used to detect spatial heterogeneity (patches) in the distribution of Calanus spp. Positive spatial autocorrelation was detected on scales up to $1.2 \mathrm{~km}$ for C. finmarchicus stages CIII-CV and for C. glacialis CIV and CV, but was rarely detected for the younger stages. This suggests that the tendency to form patches varies with ontogeny in Calanus spp. At an adjacent little auk colony, the diet prey composition from 30 gular pouches of little auks returning from feeding trips was investigated. Calanus glacialis CIV and CV were numerically dominant in the prey samples, while C. finmarchicus CIV which was dominant in the net samples did not contribute to the little auk diet. This could suggest selective feeding, a detection of patches beyond the scale of our survey, feeding beyond the sampling area or a combination of these factors. Large Calanus abundance differences within the sampling grid underline the necessity of a proper choice of grid size, in this case $2 \mathrm{~km}$ between stations.
\end{abstract}

Key words: Zooplankton patchiness, spatial autocorrelation, Alle alle, predator-prey relationship, seabirds, ontogenetic variability

\section{Introduction}

Spatial heterogeneity of marine zooplankton can be substantial (Hardy 1936; Mann \& Lazier 2006). Characteristic horizontal length scales of plankton patches range from less than $1 \mathrm{~m}$ to more than $10^{4} \mathrm{~m}$ (Legendre et al. 1986; Tsuda et al. 1993; Currie et al. 1998; Mann \& Lazier 2006, see Table I for details). Such variability can complicate interpretations of ecological data sets obtained from a limited number of sampling stations as such data may not adequately capture relevant meso- and fine-scale spatial variability (Hembre \& Megard 2003). Yet ecological studies often extrapolate data based on only a few sampling locations that at best reflect variability on one or a restricted number of spatial scales. Such investigations may produce over-smoothed data sets that render the detection of ecologically significant variability unlikely and may potentially lead to biased interpretations (Young et al. 2009). It is therefore of importance to design the sampling scheme in a way that captures the variability relevant to the processes of interest (Tsuda et al. 1993; Hembre \& Megard 2003; Molinero et al. 2008; Young et al. 2009).

Patchiness of planktonic organisms is caused by a variety of biotic (e.g. primary productivity patterns, migratory behaviour) and abiotic (e.g. oceanic gyres, coastal eddies, tidal fronts, Langmuir cells, microscale turbulence) factors on different scales (PinelAlloul 1995).

For small planktonic organisms (e.g. copepods), some processes underlying population dynamics (e.g. mate localization, migration) operate on spatial scales of $<10^{-2} \mathrm{~m}$ (e.g. Pinel-Alloul 1995; Pitchford \& Brindley 2001; Saito \& Kiørboe 2001; Kiørboe et al. 2005; Weimerskirch 2007). Other ecologically

${ }^{\star}$ Correspondence: Daniel Vogedes, Department of Arctic and Marine Biology, University of Tromsø, 9037 Tromsø, Norway. E-mail: Daniel.Vogedes@uit.no

Published in collaboration with the Institute of Marine Research, Norway

(Accepted 10 fune 2013; Published online 2 fanuary 2014; Printed 15 fanuary 2014)

(C) 2013 The Author(s).

Published by Taylor \& Francis. This is an Open Access article distributed under the terms of the Creative Commons Attribution License (http:// creativecommons.org/licenses/by/3.0), which permits unrestricted use, distribution, and reproduction in any medium, provided the original work is properly cited. The moral rights of the named author(s) have been asserted. 
significant processes such as predator-prey interactions can operate on a wide range of scales, from the millimetre scale covered by foraging fish larvae to the $>100 \mathrm{~km}$ covered by right whales feeding on copepods (Beardsley et al. 1996; Pendleton et al. 2009; Young et al. 2009). To meet their energetic demands, many predatory species depend on the occurrence of prey patches of appropriate size to obtain sufficiently high feeding rates (e.g. Beardsley et al. 1996); thus, knowledge about spatial heterogeneity is crucial for these kinds of studies. While it is a wellknown phenomenon that plankton occurs in patches on different scales, to our knowledge there have been no studies looking into patch size and the ecological consequences of patchiness in an Arctic fjord system.

The little auk (Alle alle Linnaeus, 1758) is an avian planktivore that depends on a lipid rich diet of zooplankton associated with Arctic water masses (Karnovsky et al. 2003; Steen et al. 2007; Brown et al. 2012). Species composition detected by in situ sampling of available prey in the feeding areas of the little auk, however, tends to vary considerably from compositions found in the little auk diet. In the diet, often the frequency of occurrence of the relatively larger Arctic calanoid copepods of the genus Calanus tends to be appreciably higher than in plankton samples (Golovkin et al. 1972; Bradstreet 1982; Steen et al. 2007). Little auk diet in Arctic Canada contained $79 \%$ adult females of Calanus hyperboreus Krøyer, 1838 , while net tows collected on the feeding grounds contained only $20 \%$ (Bradstreet 1982). Birds sampled in Svalbard waters in a study by Steen et al. (2007) had consistently collected adult females of Calanus glacialis Jaschnov, 1955 in their gular pouches, a prey that was not detected at all in plankton net hauls in the assumed feeding grounds. The first mention of discrepancies between $A$. alle diet and available prey is probably in the article by Golovkin et al. (1972), who hypothesized that this discrepancy is caused by the birds' ability to locate and exploit spatial heterogeneity in Calanus concentrations that remain undetected by traditional zooplankton sampling strategies. Although the effects of large-scale oceanographic features such as fronts and current systems have been addressed (e.g. Karnovsky et al. 2003, 2011), until now, no study has dealt with the effects of fine- to mesoscale patchiness of Calanus on little auk feeding behaviour. Instead, zooplankton abundances from often coarse grid sampling programmes have been assumed to be representative for a large area (e.g. Steen et al. 2007).

Here we study the spatial variability in the density of Calanus spp. on a fine- to mesoscale in the vicinity of a breeding colony of $A$. alle. This enables us to give an estimate of the potential prey patch size for little auk foraging and a recommendation for the minimum
Table I. Definitions of scales for zooplankton sampling in the literature.

\begin{tabular}{|c|c|c|}
\hline Scale name & Range $(\mathrm{km})$ & Reference \\
\hline Microscale & $<0.001$ & Young et al. (2009) \\
\hline Microscale & $<0.15$ & Molinero et al. (2008) \\
\hline Fine scale & $<1$ & $\begin{array}{l}\text { This study; Weimerskirch } \\
(2007)\end{array}$ \\
\hline Small scale & $0.1->1$ & Haury (1976) \\
\hline Small scale & $<1.5$ & Tokarev et al. (1998) \\
\hline Mesoscale & $1-20$ & This study \\
\hline $\begin{array}{l}\text { Meso- to } \\
\text { megascale }\end{array}$ & $0.5-50$ & Tsuda (1993) \\
\hline Mesoscale & $0-100$ & Vilar et al. (2003) \\
\hline Mesoscale & $100-1000$ & Weimerskirch (2007) \\
\hline Coarse scale & $1-100$ & Weimerskirch (2007) \\
\hline
\end{tabular}

sampling grid size in order to assess the variability in the horizontal distribution pattern. Furthermore, we utilize our results to evaluate how the variation in zooplankton abundance throughout the sampling grid affects foraging effort for little auk parents.

\section{Material and methods}

\section{Field collections of potential zooplankton prey}

Sampling was conducted in Isfjorden, Svalbard (centre of sampling grid: $78.26^{\circ} \mathrm{N}, 15.05^{\circ} \mathrm{E}$; Figure 1), in an area adjacent to a little auk colony, where little auks were observed both on the water and diving. Similar to Karnovsky et al. (2003), we assume that birds are actively feeding in areas where they are found on the water. The relevant scale for detecting spatial heterogeneity in Calanus spp. was not known a priori. Thus, to ensure representative sampling at different spatial scales we designed an array of nested triangles (matrushka-like), each consisting of three sampling positions. In total, the design consisted of 24 sites (stations KE1-KE24, Figure 1) with a distance of $19.2 \mathrm{~km}$ (approximately the width of the fjord, broken-dashed outer lines in Figure 1) between each of the three outer stations (KE1-KE3). The next stations (KE4-KE6, connected by broken lines in Figure 1) were placed at the midpoints between the stations of the first triangle $(9.6 \mathrm{~km}$ apart). Further stations were located in the same way so as to define a series of successively smaller nested triangles (lengths $9600,4800,2400,1200,600,300$ and $150 \mathrm{~m}$, respectively). In addition, three replicate samples (CS1-CS3) were taken as close as possible to the centre of the sampling grid. Bottom depth at the 27 stations used ranged from $c .60 \mathrm{~m}$ at the stations closest to shore to $310 \mathrm{~m}$ at KE6. Sampling was conducted from three small boats operated simultaneously between $11: 45$ and 14:15, local time, on 18 July 2007. In reality, boat drift on stations reduced geographic precision, but based on GPS track logs 


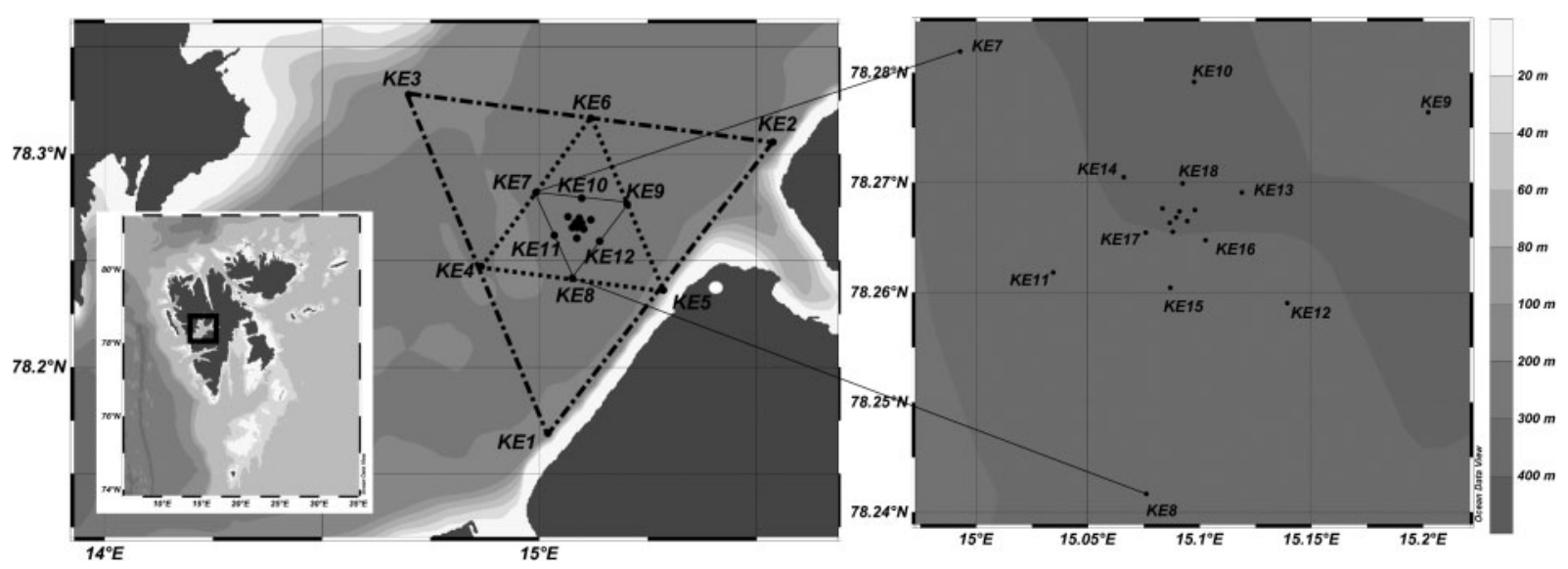

Figure 1. Sampling area with inserted overview map of Svalbard (left bottom corner). Broken and dotted lines indicate the first two nested triangles. The third triangle (KE7-9) represents the area enlarged on the right panel, within which five more matrushka-like triangles are located (but not outlined on the map). White dot indicates approximate location of little auk colony.

nearly all samples were taken within a radius of $25 \mathrm{~m}$ from the original position of each station, and as sampling was limited to $25 \mathrm{~m}$ depth, it was finished in about 2 min and little drift occurred during the net tows. Hence, this potential source of error in station location was ignored in our analysis.

Zooplankton was sampled by vertical hauls (c. 0.5 $\mathrm{m} \mathrm{s}^{-1}$ ) with hand-pulled specially manufactured WP2 plankton nets (mesh size $=200 \mu \mathrm{m}$, sampling area $=0.25 \mathrm{~m}^{2}$ ). We restricted our sampling to the upper $25 \mathrm{~m}$ of the water column as $A$. alle rarely dive deeper than $20 \mathrm{~m}$ (Falk et al. 2000; Welcker et al. 2009a; Karnovsky et al. 2011). Samples were split in two fractions using a simple box splitter (Motoda 1959). One fraction from each station was dried $\left(80^{\circ} \mathrm{C}\right.$ for $\left.24 \mathrm{~h}\right)$ and weighed to estimate total biomass (dry mass, DM). The other fraction was fixed in a $4 \%$ borax-buffered formaldehyde-inseawater solution and stored before enumeration of Calanus spp. from a randomly selected quarter of the total content (IO PAN, Sopot, Poland).

Calanus spp. copepodites were staged and identified to species (Calanus finmarchicus (Gunnerus, 1770), C. glacialis and C. hyperboreus) from the distribution of prosome length within a copepodite stage using the tables of Weydmann \& Kwasniewski (2008). Abundances were estimated assuming a $100 \%$ filtering efficiency of the plankton nets. One zooplankton sample was lost (\#22).

We monitored depth-resolved temperature and salinity by three temperature and salinity profilers (SAIV CTD profilers, one SD202 unit and two SD204 units, SAIV A/S, Bergen, Norway) attached to the cod end of each of the plankton nets. The CTD profiles were also used to verify the actual depth of the zooplankton net. The CTDs were intercalibrated based on a simultaneous deployment where all three instruments were mounted together.
Temperature measurements were identical to the first decimal point and therefore required no correction. The largest difference in salinity measurements was 0.5 PSU and we corrected salinity by a factor based on the offset between each CTD and the mean salinity obtained from all three instruments.

\section{Field collection of Alle alle diet samples}

Little auk chick diet samples were collected from 30 breeding Alle alle during the late chick-rearing period between 17 and 27 July 2007. Birds were captured with mist nets from the bird cliff in Isfjorden (Figure 1) and the contents of the gular pouches (a small sack below the beak, used to store and transport prey back to the colony for chick provisioning) were immediately gently scooped out with a small spoon into plastic bottles. Samples were preserved in a $4 \%$ formaldehyde-in-seawater solution for later analysis. In the laboratory, diet samples were rinsed with distilled water through a $200 \mu \mathrm{m}$ sieve. Random subsamples were taken and prey items were identified to the lowest possible taxonomic level and counted. Subsampling was repeated until a minimum of 100 individuals were counted. Calanus spp. identification was carried out by the same methodology as used for sea samples. Of the Calanus prey, $23.1 \%$ could not be ascertained to species or developmental stage and were not used in the numerical analysis. For the analysis we chose to focus mainly on Calanus glacialis and C. finmarchicus, due to the fact that the larger C. hyperboreus were only represented in the nets in very small numbers (see Table II). Furthermore, it has previously been documented that $C$. glacialis is the most important prey species for the little auks (Karnovsky et al. 2003; Steen et al. 2007). 
Table II. Abundance of Calanus spp. copepodites and adult females (AF) (ind. $\mathrm{m}^{-3}$ ) and total net caught biomass (mg $\mathrm{m}^{-3} \mathrm{dry}$ mass, $\mathrm{DM})$ at the stations. CS1-CS3 indicate central stations. n/a, lost sample.

\begin{tabular}{|c|c|c|c|c|c|c|c|c|c|c|c|c|c|c|c|}
\hline \multirow[b]{2}{*}{ Station } & \multicolumn{6}{|c|}{ Calanus finmarchicus } & \multicolumn{6}{|c|}{ C. glacialis } & \multicolumn{2}{|c|}{ C. hyperboreus } & \multirow[b]{2}{*}{ DM } \\
\hline & CI & CII & CIII & CIV & $\mathrm{CV}$ & $\mathrm{AF}$ & CI & CII & CIII & CIV & $\mathrm{CV}$ & $\mathrm{AF}$ & CIII & CIV & \\
\hline KE1 & 26 & 69 & 170 & 98 & 56 & 3 & 7 & 16 & 56 & 105 & 49 & - & - & 1 & 20 \\
\hline KE2 & 54 & 71 & 114 & 141 & 76 & 5 & - & 16 & 38 & 152 & 92 & - & - & 5 & 20 \\
\hline KE3 & 54 & 92 & 218 & 212 & 43 & - & - & 43 & 43 & 218 & 60 & - & - & - & 26 \\
\hline KE4 & 27 & 87 & 174 & 321 & 103 & - & - & 6 & 0 & 103 & 114 & - & - & 6 & 33 \\
\hline KE5 & 16 & 61 & 98 & 94 & 110 & - & - & 4 & 49 & 139 & 102 & - & - & 4 & 29 \\
\hline KE6 & 56 & 85 & 118 & 134 & 46 & - & - & 7 & 3 & 62 & 26 & - & - & - & 16 \\
\hline KE7 & 35 & 55 & 118 & 181 & 40 & - & - & - & 5 & 65 & 15 & - & 3 & - & 23 \\
\hline KE8 & 52 & 183 & 340 & 372 & 124 & - & - & 13 & 26 & 314 & 202 & - & - & - & 36 \\
\hline KE9 & 41 & 213 & 435 & 369 & 156 & - & - & - & 25 & 287 & 148 & - & - & - & 57 \\
\hline KE10 & 32 & 112 & 880 & 1024 & 256 & - & - & - & 64 & 576 & 400 & - & - & - & 115 \\
\hline KE11 & 68 & 136 & 361 & 327 & 116 & - & 7 & 27 & 55 & 313 & 143 & - & - & - & 34 \\
\hline KE12 & 39 & 170 & 425 & 496 & 98 & - & - & 33 & 72 & 255 & 137 & - & - & 7 & 39 \\
\hline KE13 & 47 & 73 & 303 & 424 & 126 & 5 & - & 21 & 26 & 235 & 120 & - & - & 5 & 41 \\
\hline KE14 & 52 & 118 & 379 & 483 & 144 & 7 & - & 13 & 65 & 366 & 255 & - & - & - & 59 \\
\hline KE15 & 16 & 196 & 539 & 506 & 212 & - & - & - & 33 & 425 & 196 & - & - & 8 & 65 \\
\hline KE16 & 13 & 72 & 314 & 581 & 229 & 3 & - & - & 26 & 346 & 281 & - & - & - & 88 \\
\hline KE17 & 16 & 141 & 471 & 408 & 188 & 3 & - & 16 & 78 & 298 & 243 & - & - & - & 41 \\
\hline KE18 & 39 & 72 & 346 & 503 & 222 & - & - & - & 52 & 340 & 287 & - & - & - & 85 \\
\hline KE19 & 63 & 94 & 351 & 402 & 75 & - & - & 6 & 63 & 226 & 232 & 3 & - & - & 47 \\
\hline KE20 & 36 & 45 & 193 & 381 & 157 & 9 & - & - & 4 & 152 & 99 & - & - & - & 47 \\
\hline KE21 & 52 & 85 & 261 & 359 & 209 & - & - & 13 & 46 & 242 & 170 & - & - & - & 46 \\
\hline KE22 & $\mathrm{n} / \mathrm{a}$ & $\mathrm{n} / \mathrm{a}$ & $\mathrm{n} / \mathrm{a}$ & $\mathrm{n} / \mathrm{a}$ & $\mathrm{n} / \mathrm{a}$ & $\mathrm{n} / \mathrm{a}$ & $\mathrm{n} / \mathrm{a}$ & $\mathrm{n} / \mathrm{a}$ & $\mathrm{n} / \mathrm{a}$ & $\mathrm{n} / \mathrm{a}$ & $\mathrm{n} / \mathrm{a}$ & $\mathrm{n} / \mathrm{a}$ & $\mathrm{n} / \mathrm{a}$ & $\mathrm{n} / \mathrm{a}$ & $\mathrm{n} / \mathrm{a}$ \\
\hline KE23 & 31 & 94 & 314 & 389 & 188 & - & - & 6 & 63 & 446 & 245 & - & - & - & 94 \\
\hline KE24 & 46 & 124 & 392 & 327 & 157 & - & - & 7 & 46 & 359 & 157 & - & - & 7 & 59 \\
\hline CS1 & 10 & 98 & 381 & 522 & 381 & - & - & 10 & 131 & 653 & 653 & - & - & - & 134 \\
\hline $\mathrm{CS} 2$ & 49 & 65 & 408 & 506 & 171 & - & - & 8 & 58 & 474 & 417 & - & - & - & 95 \\
\hline $\mathrm{CS} 3$ & 8 & 41 & 319 & 588 & 319 & - & - & - & 33 & 474 & 515 & - & - & - & 98 \\
\hline Mean & 38 & 102 & 324 & 390 & 154 & 1 & 1 & 10 & 45 & 293 & 206 & 0 & 0 & 2 & 56 \\
\hline Variance & 29 & 2117 & 26,212 & 37,230 & 7546 & 6 & 3 & 120 & 795 & 24,787 & 26,040 & 0 & - & 5 & 1090 \\
\hline $95 \% \mathrm{CI}$ & 8 & 20 & 73 & 86 & 37 & 1 & 1 & 5 & 12 & 68 & 67 & 0 & 0 & 1 & 14 \\
\hline
\end{tabular}

Data analysis: contour plots of physical properties and species abundance

To visualize variability in the physical properties of the study area and the species and stage structure of Calanus spp. we computed and plotted contour charts and maps using the Ocean Data View software package v. 4.4.4 - 2012 (Schlitzer 2011) with contour interpolations done by the DIVA plug-in V 4.3.0 (Troupin et al. 2009). Due to the increasing sampling resolution towards the centre of the grid, single stations with extreme values towards the centre tend to be smoothed out by surrounding stations; thus, the smoothed figures near the centre stations should be interpreted with care. Temperature and salinity were plotted as mean values for the entire sampling depth $(25 \mathrm{~m})$.

\section{Analysis of spatial heterogeneity}

Similarity between stations and grouping of stations was tested with hierarchical cluster analysis and SIMilarity PERcentage (SIMPER) computation and the presence of group structure with the SIMPROF (SIMililarity PROfile; Clarke et al. 2008) test of the PRIMER software package v. 6.1.6 (PRIMER-E Ltd, Plymouth, UK, 2006). All PRIMER tests were run on square root-transformed abundance data to even out the influence of extreme abundance values.

To quantify spatial heterogeneity of prey, we tested for spatial autocorrelation by estimating the spatial autocorrelation coefficient Moran's I (Moran 1950) on Calanus spp. copepodite stages that appeared in $>50 \%$ of the sampled stations. The Moran's I statistics for a group of stations of characteristic separation distance $(d)$ is computed according to Legendre \& Legendre (1998) from

$$
\begin{aligned}
I(d)= & {\left[W^{-1} \sum_{h=1}^{n} \sum_{i=1}^{n} w_{h i}\left(y_{h}-\bar{y}\right)\left(y_{i}-\bar{y}\right)\right] } \\
& {\left[n^{-1} \sum_{i=1}^{n}\left(y_{i}-\bar{y}\right)^{2}\right]^{-1} \text { for } \mathrm{h} \neq 1 . }
\end{aligned}
$$

Here, $y_{h}$ and $y_{i}$ define observed densities at stations $i$ and $h$, respectively. $W$ is the sum of all weights $w_{h i}$ set to 1 for combinations of $i$ and $h$ that belong to 

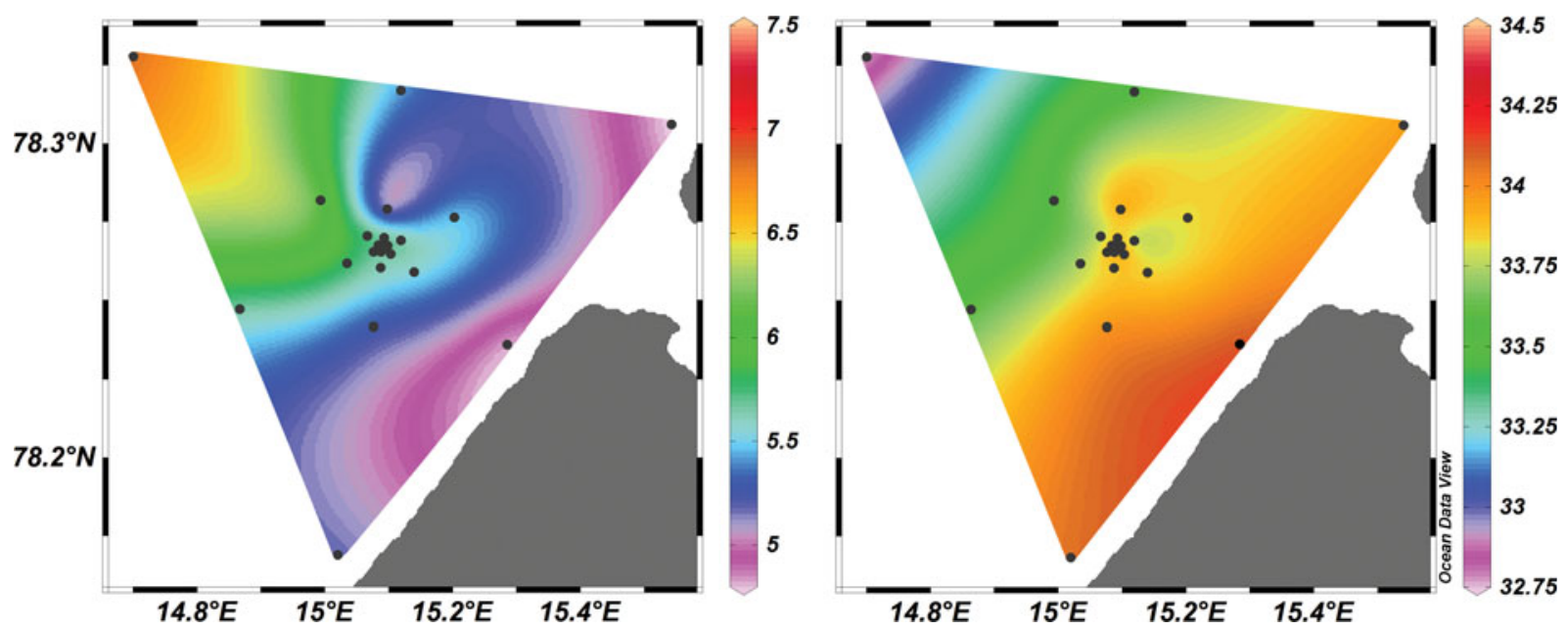

Figure 2. Temperature $\left({ }^{\circ} \mathrm{C}\right.$, left) and salinity (PSU, right) averaged over the zooplankton sampling depth of $25 \mathrm{~m}$.

geographical distance class $d$ and 0 otherwise, so that separate statistics are computed for stations grouped according to separation distance.

Values of Moran's I typically range from approx. 1 (positive autocorrelation) to -1 (negative autocorrelation) with an expected value of $-1(n-1)^{-1}$, where $n$ is the number of localities in the data set. In this analysis, pairs of similar distances are grouped into distance classes. The data set consisted of 26 localities, which we divided into eight distance classes with similar numbers (78 or 80 ) of station pairs (see Table IV for distance classes). For statistical testing we used the SAM software package v. 4 (Rangel et al. 2010, http://www.ecoevol.ufg.br/sam).

For the situation where significant positive autocorrelations were detected for smaller separation distance classes but not for larger separation distance classes, we take the spatial distance where the spatial autocorrelation function equals zero to be an estimate of the characteristic length scale of a patch.

\section{Prey size selection: Ivlev's electivity index}

Unfortunately, we lack data on handling time and energetic costs for selective feeding, but in order to explore whether size differences in prey could account for the observed prey selection we calculated Ivlev's electivity index $E=(r-p)(r+p)^{-1}$ (Ivlev 1961), where $r$ and $p$ are proportional contributions of each prey type in the diet and environment, respectively, relative to Calanus prey size (average prosome length (PL) by developmental stage).

\section{Results}

\section{Hydrography}

The main hydrographical trend recorded in the study area was a gradient from colder $\left(5-6^{\circ} \mathrm{C}\right)$, more saline $(34-34.3 \%$ ) water in the southeastern part of the sampling grid towards warmer $\left(6.5-7^{\circ} \mathrm{C}\right)$, less saline $(32.8-33.5 \%$ ) water in the northwestern part (Figure 2). In addition, a body of colder, more saline water was detected near the central area of the sampling grid. The thermocline and halocline were located between 7 and $13 \mathrm{~m}$ at all stations. Variability in physical properties was most pronounced closer to the surface, and generally decreased towards $25 \mathrm{~m}$ depth. Due to the overall horizontal pattern being similar at different depths, in Figure 2 we present only the average over the entire water column, not separate depth layers.

\section{Calanus abundance and total biomass (dry mass)}

Mean abundance increased from stage CI to CIV for Calanus finmarchicus from 38 to 390 ind. $\mathrm{m}^{-3}$ and for Calanus glacialis from 0.3 to 293 ind. $\mathrm{m}^{-3}$, while the counts for $C$. glacialis were generally lower than for C. finmarchicus (Table II). Variance was highest for C. finmarchicus CIV, followed by CIII and C. glacialis $\mathrm{CV}$ and $\mathrm{CIV}$.

Abundance of C. finmarchicus CIV peaked in concentration at station KE10 (1024 ind. $\mathrm{m}^{-3}$, Figure 3, Table II) and $\mathrm{CV}$ at one of the central stations (CS3, 319 ind. $\mathrm{m}^{-3}$ ). Across the sampling area, $C$. glacialis $\mathrm{CIV}$ and $\mathrm{CV}$ were most numerous at a central station (CS1, 653 ind. $\mathrm{m}^{-3}$ for both stages), with the abundance at the other two central stations being somewhat lower (CS2 and CS3, 416 and 514 ind. $\mathrm{m}^{-3}$, respectively). The abundance throughout the rest of the sampling grid was also similar for both stages, with another peak at KE10.

Of the potential little auk Calanus spp. prey, adult stages were rarely encountered in the samples $(<1 \%$ for all species). Calanus glacialis $\mathrm{CV}$ contributed between $5 \%$ and $27 \%$ of all net-caught Calanus: $C$. 

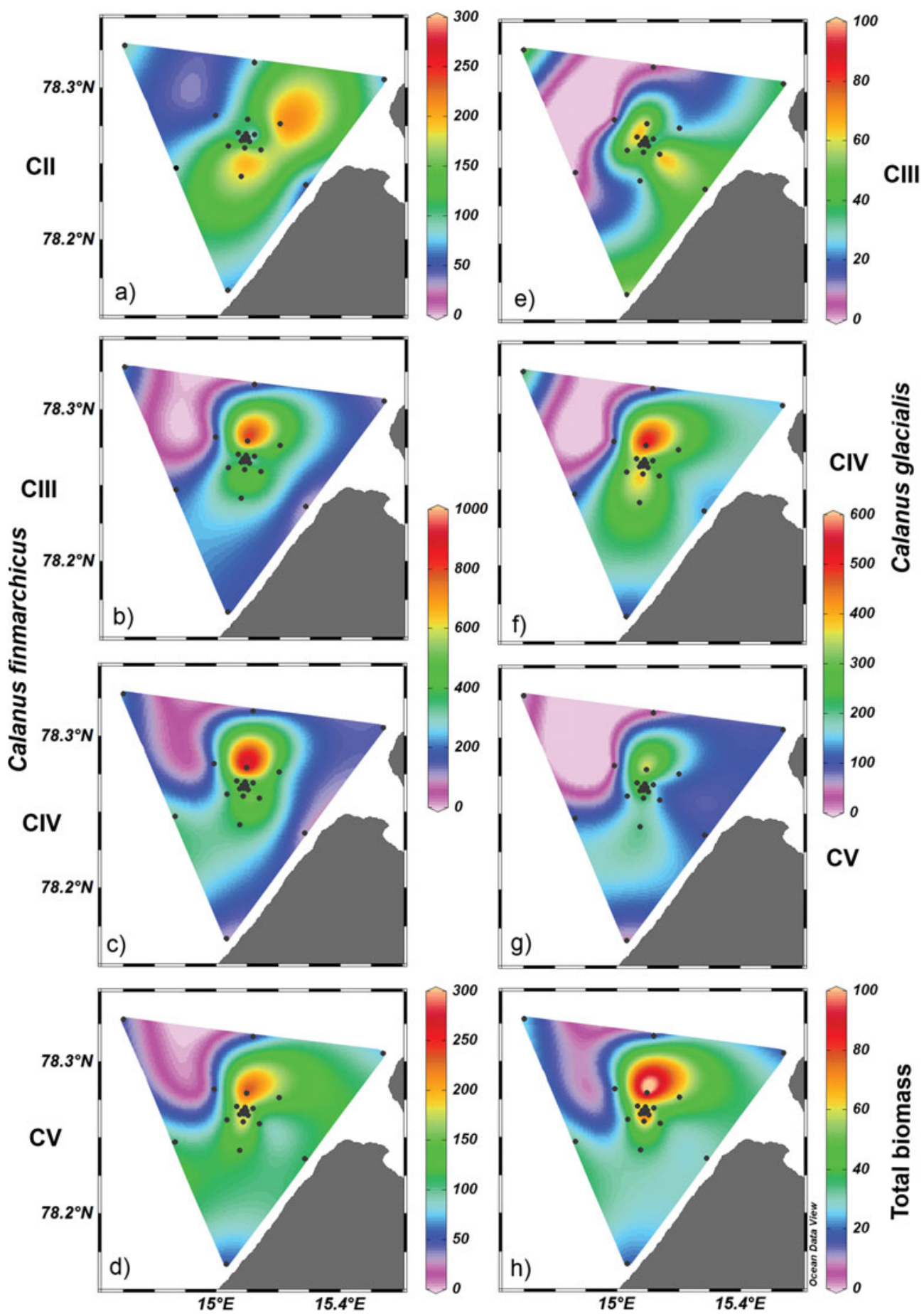

Figure 3. Calanus finmarchicus $\mathrm{CII}-\mathrm{CV}(\mathrm{a}-\mathrm{d})$, Calanus glacialis $\mathrm{CIII}-\mathrm{CV}(\mathrm{e}-\mathrm{g})$ ind. $\mathrm{m}^{-3}$, and total dry mass $\mathrm{m}^{-3}$ of all samples from 25-0 m (h). Note the different scales.

glacialis CIV 16-41\%, C. finmarchicus CV 8-25\%, C. finmarchicus CIV 21-60\% and Calanus hyperboreus $<1 \%$ for CIV (CV were absent).

The average total plankton biomass was $56 \pm 12$ $\mathrm{mg} \mathrm{m} \mathrm{m}^{-3}$ (mean $\pm 95 \% \mathrm{CI}$ ), and it ranged from $115 \mathrm{mg} \mathrm{m}^{-3}$ at KE 10 just north of the centre stations to $16 \mathrm{mg} \mathrm{m}^{-3}$ at $\mathrm{KE} 6$, to the far north of the centre stations. In general, total biomass was low at all the outermost stations (KE $1-7 ; 16-33 \mathrm{mg} \mathrm{m}^{-3}$; Figure 3, Table II).

\section{Gular pouch contents}

All 30 gular pouches investigated contained Calanus spp. and gular pouch composition did not change in the course of the diet sampling campaign. Calanus 
Table III. Diet of Alle alle chicks in the study area based on 30 individual gular pouches. Stage is copepodite stage, Counts are total counts in all gular pouches, GP is number of gular pouches containing specimens, $\%$ is relative stage and species composition of Calanus (not applicable for other prey), PL is mean prosome length of copepods, $\mathrm{n} / \mathrm{a}$ is not applicable, and indet. indicates Calanus spp. which were too damaged to unequivocally be identified.

\begin{tabular}{|c|c|c|c|c|c|}
\hline Species & Stage & Counts & GP & $\%$ & $\mathrm{PL}(\mathrm{mm})$ \\
\hline \multirow[t]{4}{*}{ C. finmarchicus } & CIII & 0 & 0 & 0 & $\mathrm{n} / \mathrm{a}$ \\
\hline & CIV & 8 & 3 & 0.1 & 2.02 \\
\hline & $\mathrm{CV}$ & 393 & 17 & 4 & 2.85 \\
\hline & $\mathrm{AF}$ & 3 & 2 & 0 & 3 \\
\hline \multirow[t]{4}{*}{ C. glacialis } & CIII & 87 & 10 & 0.9 & 1.92 \\
\hline & CIV & 3049 & 27 & 31.2 & 2.62 \\
\hline & $\mathrm{CV}$ & 5730 & 24 & 58.6 & 3.12 \\
\hline & $\mathrm{AF}$ & 15 & 4 & 0.2 & 4 \\
\hline \multirow[t]{4}{*}{ C. hyperboreus } & CIII & 18 & 8 & 0.2 & 2.47 \\
\hline & CIV & 260 & 15 & 2.7 & 3.2 \\
\hline & $\mathrm{CV}$ & 137 & 5 & 1.4 & 4.71 \\
\hline & $\mathrm{AF}$ & 81 & 5 & 0.8 & 5.7 \\
\hline Calanus spp. (indet.) & $\mathrm{n} / \mathrm{a}$ & 536 & 24 & $\mathrm{n} / \mathrm{a}$ & $\mathrm{n} / \mathrm{a}$ \\
\hline Thysanoessa longicaudata & $\mathrm{n} / \mathrm{a}$ & 18 & 8 & $\mathrm{n} / \mathrm{a}$ & $\mathrm{n} / \mathrm{a}$ \\
\hline Thysanoessa inermis & $\mathrm{n} / \mathrm{a}$ & 31 & 8 & $\mathrm{n} / \mathrm{a}$ & $\mathrm{n} / \mathrm{a}$ \\
\hline Thysanoessa indet. & $\mathrm{n} / \mathrm{a}$ & 29 & 5 & $\mathrm{n} / \mathrm{a}$ & $\mathrm{n} / \mathrm{a}$ \\
\hline Themisto abyssorum & $\mathrm{n} / \mathrm{a}$ & 354 & 15 & $\mathrm{n} / \mathrm{a}$ & $\mathrm{n} / \mathrm{a}$ \\
\hline Themisto libellula & $\mathrm{n} / \mathrm{a}$ & 21 & 2 & $\mathrm{n} / \mathrm{a}$ & $\mathrm{n} / \mathrm{a}$ \\
\hline Themisto indet. & $\mathrm{n} / \mathrm{a}$ & 43 & 5 & $\mathrm{n} / \mathrm{a}$ & $\mathrm{n} / \mathrm{a}$ \\
\hline
\end{tabular}

glacialis $\mathrm{CV}$ was the dominant copepod prey item (58.6\% of all Calanus prey) in the gular pouch samples. Calanus glacialis developmental stage CIV accounted for $31.1 \%$, while none of the other Calanus prey contributed more than $4 \%$ to the copepod part of the diet (Table III). In five cases, the number of the pelagic hyperiid amphipod Themisto abyssorum Boeck, 1870 exceeded that of

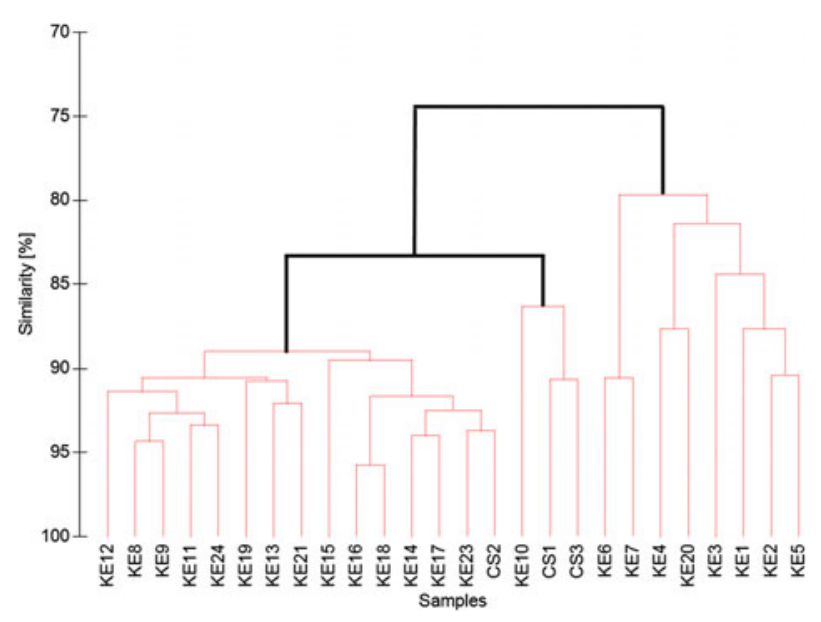

Figure 4. Group average dendrogram, based on all Calanus copepods at all stations. All data were square-root transformed. Bold lines: significant group structure. Thin lines: no significant group structure could be detected by SIMPER test $(p<0.05)$.
Calanus spp. Five Alle alle specimens had more than $85 \%$ Calanus hyperboreus, and another three specimens had 40-69\% C. hyperboreus in their gular pouches. Birds with high $C$. hyperboreus percentage also brought back a slightly larger (although not significant on $95 \%$ level) number of krill and Themisto spp. amphipods (data not presented here).

\section{Spatial structure of Calanus prey community}

Overall similarity in community structure among the sampled stations was high $(>80 \%)$ according to the SIMPER analysis used for the hierarchical cluster analysis (Figure 4). Nevertheless, there was a significant group structure in the study area, based on the rejection of the null hypothesis (all samples have medium similarity) of the SIMPROF test of all samples including all Calanus species and stages ( $P i=3.3, p<0.05$, data not presented).

The sampled stations clustered in three main groups in the hierarchical cluster analysis calculated for sample similarities taking into account all Calanus species and copepodite stages (Figure 4). Group A consisted of the two outermost triangles and an additional, more central station (KE1-7 and 20, average similarity $82 \%$ ). Group B consisted of two centre stations $(\mathrm{CS} 1,3)$ and KE10 (average similarity $88 \%$ ), and Group C contained all other stations (average similarity 90\%). In all groups, Calanus finmarchicus CIV contributed most to within group similarity $(18 \%, 20 \%$ and $19 \%$, respectively). Dissimilarity between groups was highest between A and B (35\%) with Calanus glacialis $\mathrm{CV}$ as the main contributor $(20 \%)$ to the similarity difference, intermediate between groups A and C (24\%) with $C$. finmarchicus CIII and CIV contributing equally $(16 \%)$, and lowest between groups B and C (17\%) with $C$. glacialis $\mathrm{CV}$ contributing most $(20 \%)$.

Within the study area there was heterogeneity in the distribution of all Calanus species and stages (Table IV). Positive autocorrelations prevailed between classes of separation distances ranging from 0.2 to $1.2 \mathrm{~km}$ on average. For larger classes of separation distances $(2.1-15.3 \mathrm{~km})$, negative spatial autocorrelations prevailed, most of which occurred at an average separation distance of $5.8 \mathrm{~km}$. Total netcaught biomass autocorrelated positively on the first three separation distances and negatively on the following three separation distances. As the three smallest separation distances mainly contain positive autocorrelations, while from class four onwards significantly negative autocorrelations prevail, we define the spatial horizontal extent of a patch in the study area to be up to $1.2 \mathrm{~km}$. 
Table IV. Significant spatial autocorrelations (Moran's I) for Calanus copepodite stage (CI-CV) abundances, and total net caught biomass (dry mass, DM) in Isfjorden. Spatial scale is the mean distance between stations in each grouping. Only developmental stages occurring at $>50 \%$ of stations were analysed. Key to significance levels: ${ }^{\star} p<0.05,{ }^{\star \star} p<0.01$.

\begin{tabular}{|c|c|c|c|c|c|c|c|c|c|}
\hline \multirow[b]{2}{*}{ Spatial scale $(\mathrm{km})$} & & \multicolumn{8}{|c|}{ Spatial scale $(\mathrm{km})$} \\
\hline & & 0.2 & 0.6 & 1.2 & 2.1 & 4 & 5.8 & 8.7 & 15.3 \\
\hline Number of classes & & 78 & 80 & 78 & 80 & 78 & 80 & 78 & 80 \\
\hline \multirow[t]{5}{*}{ C. finmarchicus } & $\mathrm{CI}$ & & $0.05^{\star}$ & & & & & & \\
\hline & CII & $0.2^{\star}$ & $-0.15^{\star \star}$ & $-0.18^{\star}$ & & & & & \\
\hline & CIII & & & $0.18^{\star \star}$ & $0.11^{\star \star}$ & $-0.25^{\star \star}$ & $-0.26^{\star}$ & $-0.14^{\star}$ & \\
\hline & CIV & & $0.14^{\star \star}$ & $0.28^{\star \star}$ & & $-0.22^{\star \star}$ & $-0.36^{\star \star}$ & $-0.19^{\star \star}$ & \\
\hline & CV & $0.27^{\star \star}$ & $0.25^{\star \star}$ & & $-0.15^{\star \star}$ & & $-0.44^{\star \star}$ & & \\
\hline \multirow[t]{4}{*}{ C. glacialis } & CII & $0.17^{\star}$ & & $-0.36^{\star \star}$ & $0.04^{\star \star}$ & $0.08^{\star \star}$ & & & \\
\hline & CIII & & & $0.09^{\star \star}$ & $-0.27^{\star \star}$ & $0.1^{\star \star}$ & & & \\
\hline & CIV & & $0.18^{\star \star}$ & $0.22^{\star \star}$ & $-0.15^{\star \star}$ & & $-0.57^{\star \star}$ & & \\
\hline & $\mathrm{CV}$ & $0.28^{\star \star}$ & $0.06^{\star}$ & & $-0.23^{\star \star}$ & & $-0.42^{\star \star}$ & & \\
\hline Biomass & $\mathrm{DM}$ & $0.25^{\star \star}$ & $0.27^{\star \star}$ & $0.15^{\star \star}$ & $-0.13^{\star}$ & $-0.15^{\star}$ & $-0.53^{\star \star}$ & & \\
\hline
\end{tabular}

\section{Discussion}

Causes of variability in the distribution of Calanus $s p p$.

Our main conclusion from the present study is that the older stages of Calanus spp. form patches at scales from 0.2 to $1.2 \mathrm{~km}$. We did not find a comparable pattern for the younger stages, indicating a potential ontogenetic variability in the tendency to form patches. However, sample sizes of younger stages might have been too small to detect patches at relevant scales (see discussion below). Because this observed pattern is species-independent, an explanation could be that size is the determining factor. As general distribution patterns of plankton are largely driven by advection (Mann \& Lazier 2006), it is likely that the observed variability reflects an amplification of the advection signal caused by variation in vertical distribution between early and later developmental stages. Early copepodite stages often maintain a vertical position closer to the surface than do the later stages (Eiane \& Ohman 2004; Daase et al. 2008). Copepodites of the older stages are larger and better swimmers (Greene \& Landry 1985; Eiane \& Ohman 2004), as the number of appendages used for swimming increases with the progression of developmental stage. Also, as the larger body size of later developmental stages is associated with increased susceptibility to visually orienting planktivores (Brooks \& Dodson 1965; Aksnes \& Utne 1997), larger forms may be forced to trade off food intake and mortality risk by choosing a different vertical position than the smaller forms. Patch sizes for the older stages in the Isfjorden system were within the scale-range detected by other studies for other species (e.g. Tsuda et al. 1993; Young et al. 2009).

The presence of cyclonic, eddy-like structures located in the central part of the Isfjorden system
(Ledang 2009) could account for local upwelling events that transport deeper dwelling specimens to surface waters and create a patch of larger specimens close to surface, which we observed. Additional data obtained from an autonomous underwater vehicle (equipped with $\mathrm{CTD}, \mathrm{ADCP}$ and fluorescence sensor) operated in the same area during the sampling campaign (Mark Moline, pers. comm.) gave a strong signal of colder water being transported upwards in the vicinity of stations KE710-9. This upwelling of colder water coincided with a shallower chlorophyll maximum and an elevation of the zooplankton sound scattering layer in that area (unpublished data). Also, Nilsen et al. (2008) describe rotational dynamics as an important factor for hydrographic forcing in the Isfjorden system, with water masses flowing in along the southern and out along the northern side.

However, attempts to relate Calanus abundance to water temperature or salinity (averaged values for 25 $\mathrm{m}$ as used in Figure 2) revealed no clear patterns in the current data set: only in one case (Calanus finmarchicus $\mathrm{CV}$ ) did we observe a positive association (Pearson correlation between ln-transformed abundance and salinity, $R=0.50, p<0.01$, d.f. $=$ $24)$; thus, physical factors do not seem to be the major driving force for the observed clusters. Studies of zooplankton patchiness in Conception Bay, Newfoundland (Young et al. 2009), and in the western North Pacific (Tsuda et al. 1993) also failed to detect clear relationships between fine-scale patterns in zooplankton abundance and water temperature.

The late copepodite stages of $C$. finmarchicus and C. glacialis contributed significantly to the distribution of total biomass in the study area. We found that biomass (DM) was positively correlated with abundance of copepodite stages CIII-CV of C. finmarchicus and C. glacialis, but not with earlier 
stages, adult females, or with C. hyperboreus abundance. While the abundance of Calanus spp. and copepodite stages showed considerable variability among stations (Table II), the overall pattern suggests increasing abundances towards the central part of the fjord (Figure 3). This is also reflected in the three main clusters from the similarity analysis (Figure 4): total abundance of Calanus in these clusters (peripheral stations, more central stations, stations in the very centre of the grid) differed remarkably (mean $\pm 95 \%$ CI): $769.0 \pm 166.6, \quad 1737.9 \pm 131.8$ and $2826.6 \pm 679.0$ ind. $\mathrm{m}^{-3}$, respectively.

Young et al. (2009) detected zooplankton patchiness (not resolved to copepodite stages) on scales from $10 \mathrm{~km}$ down to less than $1 \mathrm{~m}$, and Tsuda et al. (1993) found that more than $75 \%$ of the patches on a $2500-\mathrm{km}$ transect were smaller than $500 \mathrm{~m}$ in length, while the maximum patch length was $6.6 \mathrm{~km}$ when studying the distribution patterns of Neocalanus cristatus (Krøyer, 1848) copepodite stage CV. In what Tsuda et al. (1993) refer to as microscale survey in the same study, a patch length of $10-20 \mathrm{~m}$ was most frequently observed for the same copepodite stage.

\section{Discrepancies between Alle alle diet and net sampling}

Calanus finmarchicus CIVs dominated in net samples, but did not contribute much to Alle alle chick diet (Tables II and III; total counts: 8 individuals). This confirms reports of discrepancies between species and stage distribution in the sea and in little auk diets reported in other studies. Karnovsky et al. (2003) found a dominance of C. finmarchicus CIV and younger in net samples as well, which were absent in gular pouches. They also report Themisto $\mathrm{sp}$. and adult krill as common prey and suggest that these fast swimmers are underrepresented in net samples. Golovkin et al. (1972), working north of Novaya Zemlya, state that little auk gular pouches contained several prey species which were rare or absent in net samples. Bradstreet (1982) found that young-of-the-year had a diet of $79 \%$ and $91 \%$ Calanus hyperboreus adult females (AF), while sea samples only consisted of $20 \%$ and $26 \%$ of that species at two stations, respectively. Steen et al. (2007) report consistently low numbers of Calanus glacialis $\mathrm{AF}$ in gular pouches, a stage that was not observed at all in net samples along a transect past the bird colony. A recent study covering a total of eight years (Kwasniewski et al. 2012) showed the coupling for C. glacialis/C. finmarchicus ratio and, in support of earlier studies, they suggested that the foraging ground of the little auk is most likely limited to the Arctic water current, separated by a hydro- graphical front, from the Atlantic water current and not mixed water masses as in our study.

As little auks rarely collect prey smaller than 2.5 $\mathrm{mm}$ (Bradstreet 1982; Weslawski et al. 1999a,b; this study), it seems likely that size is an important criterion for prey selection. While the mechanism for this prey selection remains poorly understood, elevated energy demands during the breeding season force birds to optimize their foraging efficiency. One optimization strategy could be to rigorously select for the larger, more energy rich prey (Macarthur \& Pianka 1966). The emerging pattern of Ivlev's I electivity index (Figure 5) indicates that $A$. alle selects for Calanus larger than c. $2.5 \mathrm{~mm}$ and against smaller forms irrespective of species or developmental stage. This supports the view that Calanus size is indeed a major factor influencing the diet composition in $A$. alle.

The numerically most important dietary components were $C$. glacialis CVs and CIVs. The abundance of both of these prey was significantly positively autocorrelated for $0.6-1.2 \mathrm{~km}$ (CIV) and 0.2-0.6 $\mathrm{km}(\mathrm{CV})$ average separation distance (Table IV). On all centre stations and KE10, C. glacialis CV were more abundant than $C$. finmarchicus $\mathrm{CV}$, while there were only minor differences between the concentrations of these two copepods at the other stations (Table II). This indicates that local patches of larger zooplankton in high concentrations exist close to the $A$. alle breeding colony as suggested by Golovkin et al. (1972), and we conclude that spatial heterogeneity could be an explanation for the discrepancy between diet and estimated food availability in the adjacent sea as reported elsewhere (e.g. Bradstreet 1982; Steen et al. 2007). This further emphasizes the need for high spatial resolution sampling when studying predator-prey relationships.

\section{Implications for Alle alle foraging efficiency}

To assess how the patchy distributions within our sampling grid would affect feeding efficiency of a planktivorous predator, we estimated the potential energy available for foraging little auks in the different parts of the sampling grid and relate this to literature data on the daily energy demand of chicks and adults. We based our calculations on the four most common functional groups of Calanus (stages and species) prey items encountered in the 30 gular pouches (see Table III) and the average energy content on Vogedes et al. (2010): Calanus glacialis CIV (59\%, $\left.10 \mathrm{~J}_{\text {ind. }}{ }^{-1}\right)$, C. glacialis CV $\left(31 \%, 16 \mathrm{~J}^{\text {ind. }}{ }^{-1}\right)$, Calanus finmarchicus $\mathrm{CV}(4 \%$, $10 \mathrm{~J}$ ind. $\left.{ }^{-1}\right)$, Calanus hyperboreus $\mathrm{CIV}(3 \%, 16 \mathrm{~J}$ ind. ${ }^{-1}$ ). The energy per $\mathrm{m}^{3}$ seawater by these 


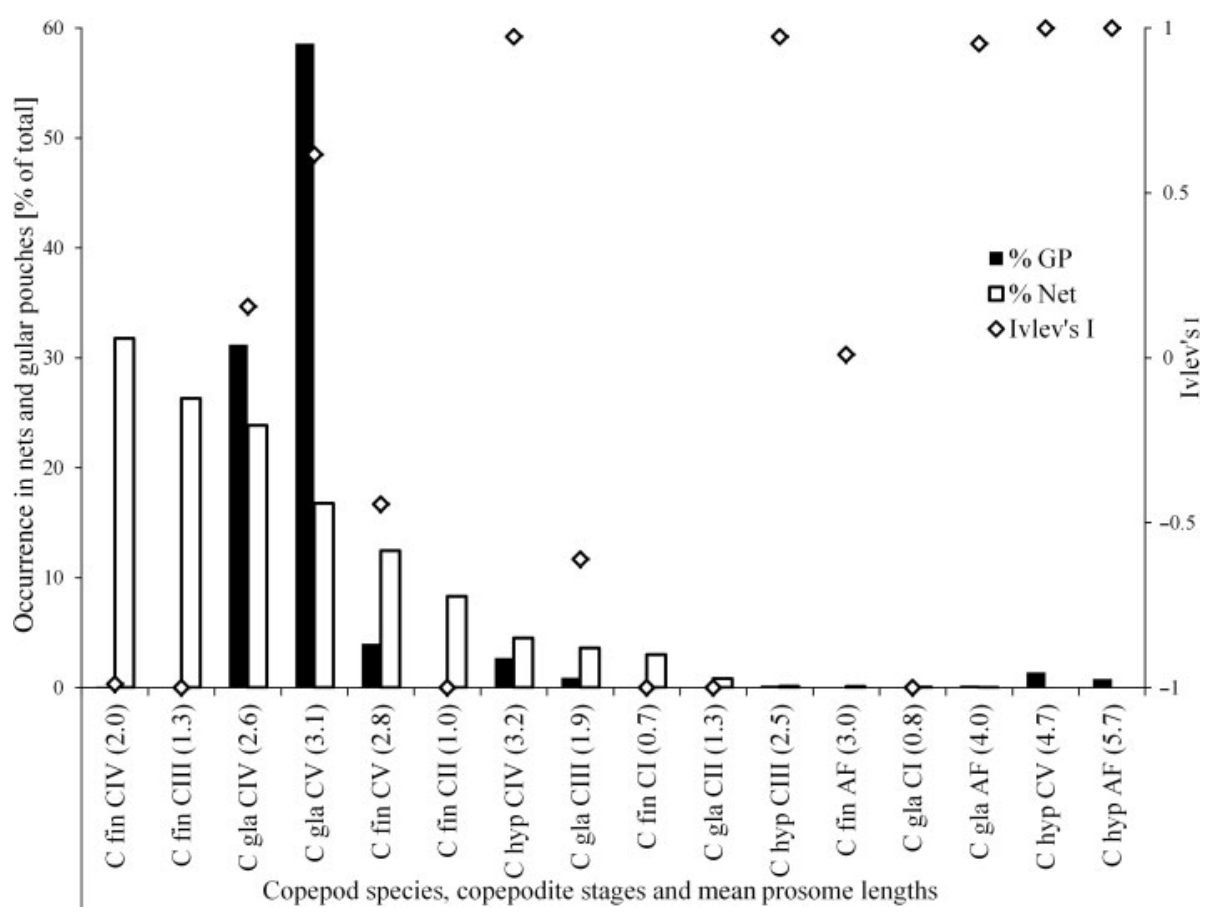

Figure 5. Average percentage of stages of Calanus spp. in 26 plankton net samples ('\% Net', white bars), 30 gular pouches of little auks (Alle alle) from the breeding colony in the vicinity of the study area (\% GP, dark bars), and Ivlev's electivity index ('Ivlev's I', diamonds) for each stage and species of Calanus. In parentheses average prosome length in $\mathrm{mm}$. The $23.1 \%$ Calanus indet. prey are not included; $\mathrm{C}$ fin $=$ Calanus finmarchicus; $\mathrm{C}$ gla $=$ C. glacialis; $\mathrm{C}$ hyp $=$ C. hyperboreus .

species/stages ranges from $1.3 \mathrm{~kJ} \mathrm{~m}^{-3}$ at station $\mathrm{KE} 7$ to $20.8 \mathrm{~kJ} \mathrm{~m}^{-3}$ at station CS1.

Published estimates of the energy demand for Alle alle chicks during rearing ranges between 104 and $350 \mathrm{~kJ} \mathrm{day}^{-1}$ (Konarzewski et al. 1993; Wojczulanis et al. 2006; Jakubas et al. 2007) and the daily energy expenditure for breeding little auks is estimated to be $600-800 \mathrm{~kJ} \mathrm{day}^{-1}$ (Gabrielsen et al. 1991; Harding et al. 2009; Welcker et al. 2009b).

When collecting food in the high-energy area, a little auk would have to clear every prey item out of 5-18 $\mathrm{m}^{3}$ of seawater and in the low-energy area out of $100-350 \mathrm{~m}^{3}$ of seawater, respectively, for the lowest and highest estimated chick energy demand. In addition to this, the parent little auks need to forage for self-maintenance. These numbers illustrate that it is essential for a little auk to find patches of high food concentrations to optimize foraging time spent under water. Single point sampling as in Steen et al. (2007) might give misleading results, both in terms of quantity and quality of the potential prey.

We cannot, of course, rule out that there are patches of higher abundances of prey items on even smaller horizontal scales, or in particular in the vertical, which we did not resolve at all in our study. If, for example, larger copepodite stages have a tendency to accumulate near the layer of chlorophyll maximum, it is likely that the actual ind. $\mathrm{m}^{-3}$ value is much higher than presented here. The fact that eight specimens of $A$. alle had C. hyperboreus in their gular pouches, which were virtually absent in the net samples (Figure 5) and the rest of the gular pouches (Table III), suggests that some of the birds have been on foraging trips outside the sampling area, probably returning from long foraging trips. This is indeed what was first suggested by Steen et al. (2007) and recently confirmed by GPSequipped birds from Svalbard (Jakubas et al. 2012).

One has to keep in mind though that the WP2 net undersamples $C$. hyperboreus, which are good swimmers and might escape the approaching net. This is why we chose to focus mainly on C. glacialis and C. finmarchicus.

\section{Concluding remarks}

Patchiness has long been recognized as a biologically significant trait in plankton ecology (Hardy 1936; Pinel-Alloul 1995), and recently ecological effects of patchiness on different scales have received increasing attention, in particular with regard to predatorprey relationships (Weimerskirch 2007). Our study indicates that dominating Alle alle prey aggregated in patches with a characteristic length scale of below $1.2 \mathrm{~km}$ (Table IV). For this particular potential feeding ground a sampling grid of less than $2 \mathrm{~km}$ would be necessary to cover the variation in the area. Given the logistical demands associated with sampling at such resolution, modern high-resolution 
sampling equipment such as continuous net-plankton pumping (Molinero et al. 2008), optical plankton recorder (Pinel-Alloul 1995; Currie et al. 1998) and acoustics (ADCP) (Pinel-Alloul 1995; Tokarev et al. 1998; Coyle 2000; Hembre \& Megard 2003) are necessary complements to traditional plankton net tows. Furthermore, the heterogeneity in horizontal distribution also raises questions about the extent and nature of vertical patchiness. A $25 \mathrm{~m}$ sampling interval in the vertical as in this study might be too coarse for predator-prey studies such as this one, and thus a finer scale in the vertical is desirable for further studies. Finally, the use of GPS and time/depth loggers on little auks should be extended to get a better idea in which areas and what time frames feeding takes place. The large difference in prey energy content per unit of seawater illustrated that little auks are highly dependent on the existence of patches of energy rich prey within the reach of short foraging trips. A possible change in current patterns that could lead to the disappearance or relocation of these patches is likely to have a great impact on the breeding success of little auks from the Bjørndalen colony.

\section{Acknowledgements}

This study is part of the synoptic ALBERT (Arctic Life: Bridging Ecosystem function using Remote Technologies) campaign, which was a collective effort of different sampling and measuring methods to gain insight into fine scale patchiness of zooplankton and phytoplankton distribution and their effects on little auks and part of the MariClim project (Marine ecosystem consequences of climate induced changes in water masses off West-Spitsbergen). The authors would like to thank three anonymous reviewers for their very helpful comments, as well as Paul E. Renaud, Øystein Varpe, Finlo Cottier and Karen Lone for comments and language proof reading throughout the writing process. We are also thankful to Sanna Majaneva and Mikko Vihtakari for their help with gular pouch sampling and sample analysis as well as for Alexey Pavlolv's help during the intensive at-sea sampling campaign. Logistics were provided by UNIS. This paper contributes to the NFR project Circa (project number 214271/ F20). Jørgen Berge was financially supported by the NFR project EWMA (project number 195160).

\section{References}

Aksnes DL, Utne ACW. 1997. A revised model of visual range in fish. Sarsia 82:137-47.
Beardsley RC, Epstein AW, Chen C, Wishner KF, Macaulay MC, Kenney RD. 1996. Spatial variability in zooplankton abundance near feeding right whales in the Great South Channel. Deep Sea Research II 43:1601-25.

Bradstreet MSW. 1982. Pelagic feeding ecology of dovekies, Alle alle, in Lancaster Sound and Western Baffin Bay. Arctic 35:126-40.

Brooks JL, Dodson SI. 1965. Predation body size and composition of plankton. Science 150:28-35.

Brown ZW, Welcker J, Harding AMA, Walkusz W, Karnovsky NJ. 2012. Divergent diving behavior during short and long trips of a bimodal forager, the little auk Alle alle. Journal of Avian Biology 43:215-26.

Clarke KR, Somerfield PJ, Gorley RN. 2008. Testing of null hypotheses in exploratory community analyses: Similarity profiles and biota-environment linkage. Journal of Experimental Marine Biology and Ecology 366:56-69.

Coyle KO. 2000. Acoustic estimates of zooplankton biomass and distribution: Application of canonical correlation to scaling of multifrequency acoustic data. Canadian Journal of Fisheries and Aquatic Sciences 57:2306-18.

Currie WJS, Claereboudt MR, Roff JC. 1998. Gaps and patches in the ocean: A one-dimensional analysis of planktonic distributions. Marine Ecology Progress Series 171:15-21.

Daase M, Eiane K, Aksnes DL, Vogedes D. 2008. Vertical distribution of Calanus spp. and Metridia longa at four Arctic locations. Marine Biology Research 4:193-207.

Eiane K, Ohman MD. 2004. Stage-specific mortality of Calanus finmarchicus, Pseudocalanus elongatus and Oithona similis on Fladen Ground, North Sea, during a spring bloom. Marine Ecology Progress Series 268:183-93.

Falk K, Pedersen CE, Kampp K. 2000. Measurements of diving depth in dovekies (Alle alle). The Auk 117:522-25.

Gabrielsen GW, Taylor JRE, Konarzewski M, Mehlum F. 1991. Field and laboratory metabolism and thermoregulation in dovekies (Alle alle). The Auk 108:71-78.

Golovkin AN, Zelikman EA, Georgiev AA. 1972. Biology and the feeding connections of little auks (Plotus alle). In: Golovkin AN, editor. Peculiarities of Biological Productivity of Waters Near Bird's Bazaars in the North of Novaya Zemlya. Leningrad: Nauka, Academy of Sciences of the USSR, p 84-91. (in Russian)

Greene CH, Landry MR. 1985. Patterns of prey selection in the cruising calanoid predator Euchaeta elongata. Ecology 66:1408-16.

Harding AMA, Egevang C, Walkusz W, Merkel F, Blanc S, Gremillet D. 2009. Estimating prey capture rates of a planktivorous seabird, the little auk (Alle alle), using diet, diving behaviour, and energy consumption. Polar Biology 32:785-96.

Hardy AC. 1936. Observations on the uneven distribution of oceanic plankton. Discovery Reports 11:511-38.

Haury LR. 1976. A comparison of zooplankton patterns in the California Current and North Pacific Central Gyre. Marine Biology 37:159-67.

Hembre LK, Megard RO. 2003. Seasonal and diel patchiness of a Daphnia population: An acoustic analysis. Limnology and Oceanography 48:2221-33.

Ivlev VS. 1961. Experimental Ecology of the Feeding of Fishes. New Haven, CT: Yale University Press. 302 pages.

Jakubas D, Wojczulanis-Jakubas K, Walkusz W. 2007. Response of dovekie to changes in food availability. Waterbirds 30:421-28.

Jakubas D, Iliszko L, Wojczulanis-Jakubas K, Stempniewicz L. 2012. Foraging by little auks in the distant marginal sea ice zone during the chick-rearing period. Polar Biology 35:73-81.

Karnovsky NJ, Kwasniewski S, Weslawski JM, Walkusz W, Beszczyska-Möller A. 2003. Foraging behavior of little auks 
in a heterogeneous environment. Marine Ecology Progress Series 253:289-303.

Karnovsky NJ, Brown ZW, Welcker J, Harding AMA, Walkusz W, Cavalcanti A, et al. 2011. Inter-colony comparison of diving behavior of an Arctic top predator: implications for warming in the Greenland Sea. Marine Ecology Progress Series 440:229-40.

Kiørboe T, Bagøien E, Thygesen UH. 2005. Blind dating - Mate finding in planktonic copepods. II. The pheromone cloud of Pseudocalanus elongatus. Marine Ecology Progress Series 300:117-28.

Konarzewski M, Taylor JRE, Gabrielsen GW. 1993. Chick energy requirements and adult energy expenditures of dovekies (Alle alle). The Auk 110:343-53.

Kwasniewski S, Gluchowska M, Walkusz W, Karnovsky NJ, Jakubas D, Wojczulanis-Jakubas K, et al. 2012. Interannual changes in zooplankton on the West Spitsbergen Shelf in relation to hydrography and their consequences for the diet of planktivorous seabirds. ICES Journal of Marine Science 69:890-901.

Ledang AB. 2009. Coupled Physical and Biological Processes Related to Mesoscale Eddy Field in Kongsfjorden and Isfjorden. Bergen: University of Bergen. 89 pages.

Legendre L, Demers S, Lefaivre D. 1986. Biological production at marine ergoclines. In: Nihoul JCJ, editor. Marine Interfaces Ecohydrodynamics. Amsterdam: Elsevier, Elsevier Oceanography Series 42:1-29.

Legendre P, Legendre L. 1998. Numerical Ecology. Oxford: Elsevier. 870 pages.

Macarthur RH, Pianka ER. 1966. On optimal use of a patchy environment. American Naturalist 100:603-09.

Mann KH, Lazier JRN. 2006. Dynamics of Marine Ecosystems. 3rd edition. Oxford: Blackwell Publishing. 512 pages.

Molinero JC, Ibanez F, Souissi S, Bosc E, Nival P. 2008. Surface patterns of zooplankton spatial variability detected by high frequency sampling in the NW Mediterranean. Role of density fronts. Journal of Marine Systems 69:271-82.

Moran PAP. 1950. Notes on continuous stochastic phenomena. Biometrika 37:17-23.

Motoda S. 1959. Devices of simple plankton apparatus. Memoirs of the Faculty of Fisheries, Hokkaido University 7:73-94.

Nilsen F, Cottier F, Skogseth R, Mattsson S. 2008. Fjord-shelf exchanges controlled by ice and brine production: The interannual variation of Atlantic Water in Isfjorden, Svalbard. Continental Shelf Research 28:1838-53.

Pendleton DE, Pershing AJ, Brown MW, Mayo CA, Kenney RD, Record NR, et al. 2009. Regional-scale mean copepod concentration indicates relative abundance of North Atlantic right whales. Marine Ecology Progress Series 378:211-25.

Pinel-Alloul B. 1995. Spatial heterogeneity as a multiscale characteristic of zooplankton community. Hydrobiologia 300:17-42.

Pitchford JW, Brindley J. 2001. Prey patchiness, predator survival and fish recruitment. Bulletin of Mathematical Biology 63:527-46.

Rangel TF, Diniz JAF, Bini LM. 2010. SAM: A comprehensive application for Spatial Analysis in Macroecology. Ecography $33: 46-50$.
Saito H, Kiørboe T. 2001. Feeding rates in the chaetognath Sagitta elegans: Effects of prey size, prey swimming behaviour and small-scale turbulence. Journal of Plankton Research 23:1385-98.

Schlitzer R. 2011. Ocean Data View. 4.4.4 - 2012. Bremerhaven: Alfred-Wegener-Institute. Computer Program.

Steen H, Vogedes D, Broms F, Falk-Petersen S, Berge J. 2007. Little auks (Alle alle) breeding in a high Arctic fjord system: Bimodal foraging strategies as a response to poor food quality? Polar Research 26:118-25.

Tokarev YN, Williams R, Piontkovski SA. 1998. Small-scale plankton patchiness in the Black Sea euphotic layer. Hydrobiologia 376:363-67.

Troupin C, Beckers J-M, Ouberdous M, Sirjacobs D. 2009. DIVA Data-Interpolating Variational Analysis. 4.3.0. Liege: SeaDataNet. Computer Program.

Tsuda A, Sugisaki H, Ishimaru T, Saino T, Sato T. 1993. Whitenoise-like distribution of the oceanic copepod Neocalanus christatus in the subarctic North Pacific. Marine Ecology Progress Series 97:39-46.

Vilar JMG, Sole RV, Rubi JM. 2003. On the origin of plankton patchiness. Physica A - Statistical Mechanics and its Applications 317:239-46.

Vogedes D, Varpe Ø, Søreide JE, Graeve M, Berge J, FalkPetersen S. 2010. Lipid sac area as a proxy for individual lipid content of arctic calanoid copepods. Journal of Plankton Research 32:1471-77.

Weimerskirch H. 2007. Are seabirds foraging for unpredictable resources? Deep Sea Research II 54:211-23.

Welcker J, Harding AMA, Karnovsky NJ, Steen H, Strøm H, Gabrielsen GW. 2009a. Flexibility in the bimodal foraging strategy of a high Arctic alcid, the little auk, Alle alle. Journal of Avian Biology 40:388-99.

Welcker J, Harding AMA, Kitaysky AS, Speakman JR, Gabrielsen GW. 2009b. Daily energy expenditure increases in response to low nutritional stress in an Arctic-breeding seabird with no effect on mortality. Functional Ecology 23:1081-90.

Weslawski JM, Koszteyn J, Kwasniewski S, Stempniewicz L, Malinga B. 1999a. Summer food resources of the little auk, Alle alle (L.) in the European Arctic seas. Polish Polar Research 20:387-403.

Weslawski JM, Stempniewicz L, Mehlum F. 1999b. Summer feeding strategy of the little auk (Alle alle) from Biørnøya, Barents Sea. Polar Biology 21:129-34.

Weydmann A, Kwasniewski S. 2008. Distribution of Calanus populations in a glaciated fjord in the Arctic (Hornsund, Spitsbergen) - The interplay between biological and physical factors. Polar Biology 31:1023-35.

Wojczulanis K, Jakubas D, Walkusz W, Wennerberg L. 2006. Differences in food delivered to chicks by males and females of little auks (Alle alle) on South Spitsbergen. Journal of Ornithology 147:543-48.

Young KV, Dower JF, Pepin P. 2009. A hierarchical analysis of the spatial distribution of larval fish prey. Journal of Plankton Research 31:687-700.

Editorial responsibility: Haakon Hop 